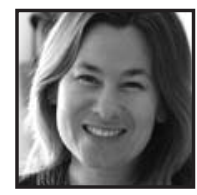

\title{
Attending to Highly Sensitive Children in the Classroom
}

\author{
Mandy Hollands, University of Saskatchewan
}

\section{ABSTRACT}

Through the storied experiences of a Highly Sensitive Child (HSC), the author creates a picture of what High Sensitivity is and how it impacts children in the classroom. Discussion focuses on attending to the needs of highly sensitive children, specifically addressing friendship, environment, discipline, stimulation, and reciprocal learning relationships. The author makes visible why it is important to create a classroom life that meets the needs of highly sensitive children and theorizes that, in doing so, the bar for attending to the wellness of all children will be raised. This article begins a conversation about highly sensitive children in the classroom, something not currently being addressed in educational literature.

\section{Introduction}

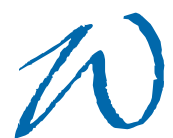

hen I speak of Highly Sensitive Children (HSC) (Aron, 2002) I find I am met with one of two responses. The first response is for someone to ask, "What is HSC?" The second response is for someone to question if, or at times assume, I am speaking of a child with a designated special need such as autism or sensory integration dysfunction, which I am not.' It has taken me some time to discover how to reply to these inquiries with thoughtfulness. I have found sharing pieces of my experience with my son, Owen, has been most helpful. In this article, I tell the story of how I experienced Owen's first year at school in Kindergarten and his entrance into a new school in Grade 3. These stories illustrate how high sensitivity presents in children in the classroom. I then work to create an understanding of what high sensitivity is and 
how HSC can be honoured in the classroom. My intention by sharing my experiences with having a highly sensitive child is that it may open the door for others to see why attending to HSC in the classroom is so impactful.

\title{
Kindergarten
}

\section{Sick}

'I cannot go to school today,'

Said little Peggy Ann McKay.

'I have the measles and the mumps,

A gash, a rash and purple bumps.

My mouth is wet, my throat is dry

I'm going blind in my right eye.

My tonsils are as big as rocks,

I've counted sixteen chicken pox

And there's one more - that's seventeen,

And don't you think my face looks

green?

My leg is cut, my eyes are blue -

It might be instamatic flu.

I cough and sneeze and gasp and choke,

I'm sure that my left leg is broke -

My hip hurts when I move my chin,

My belly button's caving in,

\author{
My back is wrenched, my ankle's \\ sprained, \\ My 'pendix pains each time it rains. \\ My nose is cold, my toes are numb, \\ I have a sliver in my thumb. \\ My neck is stiff, my spine is weak, \\ I hardly whisper when I speak. \\ My tongue is filling up my mouth, \\ I think my hair is falling out. \\ My elbow's bent, my spine ain't straight, \\ My temperature is one-o-eight. \\ My brain is shrunk, I cannot hear, \\ There is a hole inside my ear. \\ I have a hangnail, and my heart is- what? \\ What's that? What's that you say? \\ You say today is... Saturday? \\ G'bye, I'm going out to play!'
}

(Silverstein, 1974, pp. 58-59)

Looking back on my son, Owen's, start to primary at our local public school I recall it as everything I hoped it would never be. I deeply regret that I did not pull him out as soon as I recognized how bad it was for him. Some children, like Shel Silverstein's (1974) Peggy Ann McKay, just do not want to go to school some days. I imagine most people feel that sense of needing a break at some point or other throughout school, or later on in their work life. But with Owen it was different. Not wanting to go to school was a sign of his constant state of emotional distress-and I was very concerned. In a short period of time after starting Kindergarten, Owen grew terrified of his teacher, and later his school, and authority figures in general. He spoke less. He was fearful of asking questions, of making a mistake, or of doing anything that was "not allowed." 
I remember one day, after school, I suggested he climb to the top platform of the play structure. He looked at me and asked, "Is that allowed?" "Yes," I answered, and he said, "How do you know?" And then, unsatisfied with me as the authority on the climbing rules, he chose not to run off and do what I had suggested, just in case I was wrong and it was in fact not allowed. He was very anxious of breaking any rules and "getting in trouble."

His fear of his teacher and of school turned into excessive anxiety, and he began to lose sleep. I worried about him continuously and could not shake the feeling of fear that would envelop me when I dropped him off at school. Nor could I stop thinking about what I should, and could, do about the situation and the changes I was seeing in Owen at home. He developed headaches that would at times be so severe they would escalate to migraines where I would lay him on my bed, a cold cloth on his forehead, curtains drawn, lights turned out, and sit with him while he cried quietly from the pain. Now, when I look back, I think I should have known what was triggering them. It was stress. My little boy was experiencing so much stress at school that his body started to rebel. He was five years old.

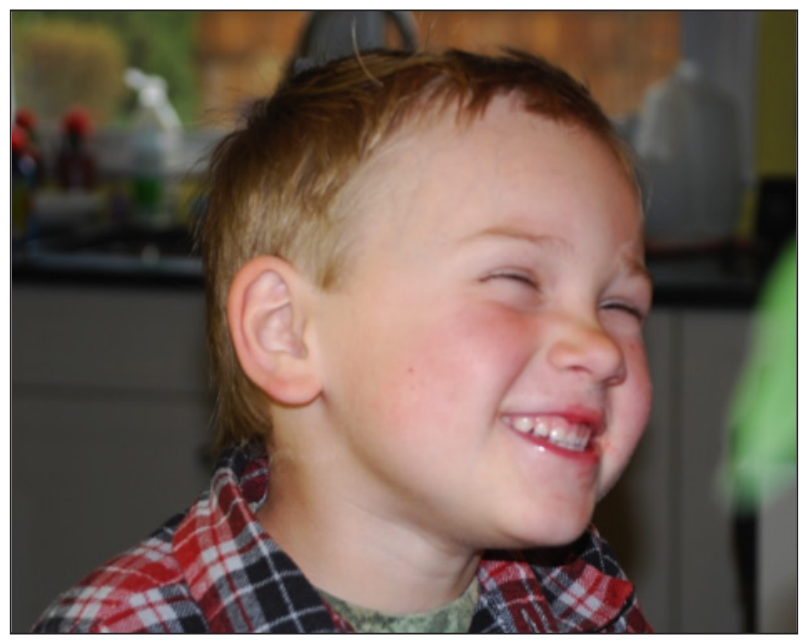

Fig. 1: Owen, Age 4

Owen sits at the little table in his bedroom. It's 7 a.m. He has pencil to paper. He's practicing, he tells me. "I need to practice," he says, "I can't get it wrong!" He cries when I tell him he doesn't need to practice his printing before he goes to school. "Yes," he sobs, "I do! I have to do it right!" 
I drop Owen off at his classroom, carefully staying outside as parents have been asked to do-though he still needs help with his shoes. I tend to linger a little after the bell. I have seen some things at home that are causing concern, so I like to peek through the window occasionally to see if I can notice any clues that may help me understand what is happening with Owen. I watch through the window, cautiously, because I feel certain this watching would be unappreciated by the teacher and administration. I drop things off at the office during school hours so I can walk past Owen's classroom and take a peek, and I come early at pick-up times, too.

Every time I look in at my son I see him, head down, at his place at the table working with pencil to paper. He is not smiling. He does not look happy. It does not appear to me that he is having fun. I feel so sad when I see this time and time again. The room has activity and play items in it but I don't see him using them.

Owen is standing in the auxiliary room at the sink in his classroom. I am watching through the uncovered section of window looking into the room. I smile at Owen. He looks nervous and hesitates to smile back at me. My mom is with me and we exchange a questioning look. Owen is washing his hands. He taps, with his elbow, an empty glass baby jar. It clacks to the floor and spins. Owen freezes. He starts to tremble in his hands, up his arms, he swallows, eyes wide. He looks at me. I smile. I mouth, "It's okay. Just pick it up." He tentatively steps one foot off of the stool and, as he reaches down, his teacher steps into view. Owen stops mid-motion for a split second. The teacher stoops and picks up the jar, as Owen has stopped his action to do so, and places the jar on the counter. She walks out. No word to Owen. Owen stands, doesn't look at my mom and me, doesn't finish washing his hands, but dries them and turns and walks out. His face is white and blank.

Owen tells me he hides at recess. It is scary at recess. There is a child that chases him. So he hides. He hid every day for two weeks. No one noticed.

Owen tells me he is afraid to use the bathroom at school.

Owen is sprawled out in the sunshine on our living room rug. He is head to head with his little friend, Rae. ${ }^{2}$ Rae is also five years old and in Kindergarten at a different school. I hear Rae chirp to Owen, "I love my teacher. She's so nice." Owen, in a tone I have never heard him use before, replies, "Not my teacher. She's cranky." He pauses in thought and adds, emphatically, "She's cranky every day!" 
I picked Owen up at the end of every morning at school. He walked out of his classroom and no longer smiled at me. He walked with his head down and did not want to talk about his day. At home, over time, he grew angrier, more anxious, and sadder. He cried when it was time to go to school and said he did not want to go, until about January, at which time he just stopped talking about it at all. What happened that made him into this sullen and sad little creature who refused to speak to me about his day? By June he was hardly the boy I knew. He was just five years old and he was broken inside. I felt broken inside, too.

I will never forget his first day of Grade 1. I promised him that he was not going to have the same teacher or be in the same classroom this year. Yet, as I walked him into the school I could see him nearly holding his breath, hand squeezed into mine, and head forward. It was once we began our turn down the primary hallway that he audibly let out his breath. He had been afraid, he said later, that I had not told him the truth. School had become a place of stress for him.

It has been three years since Owen was in Kindergarten and still I find it painful recalling my memories of that year. I wonder even now ... what if I had met with his Kindergarten teacher in a detailed way before the start of the school year to share with her Owen's high sensitivity and how it shapes him? What if I told her a story about Owen's preschool experience and the special relationship we established with his teacher, Frances? What if I had listened to my gut instinct and removed him from the class when he was obviously not well or happy there? What if I had stopped trying to make it work? What if I had trusted myself to do what Owen needed and worried less about how I would look to staff? My wonders lead me to consider what kind of teacher characteristics best suit the needs of highly sensitive students?

\section{Highly Sensitive Children (HSC)}

What is a Highly Sensitive Child? There is no one simple answer or definition that describes all aspects of high sensitivity. In her book, The Highly Sensitive Child: Helping Our Children Thrive When the World Overwhelms Them, clinical psychologist Elaine Aron (2002), discussed what does and does not characterize high sensitivity. She did not give one succinct definition for highly sensitive children as these children have many uniquely defining characteristics that, together, create a picture of how high sensitivity presents within that one individual. HSC is a personality trait, a dominant trait, yet one of the many any child possesses. HSC is not a special need, disorder, dysfunction, or diagnosable condition. I remember reading Aron's work for the first time and how surprised and relieved I felt when I read, "One such common inherited trait is high 
sensitivity, found in about 15-20 percent of children (the percentage is the same in boys and girls)" (pp xi). It was affirming to know how common this trait is, and also how important it is to have highly sensitive individuals as members of our society:

... [T]here are also advantages in having a child who is different... Some teachers, peers, and relatives will think your child's differences are marvelous. From these people your child will gain the self-esteem she will need when meeting up with some of the other people, the majority in our culture, who are less impressed with sensitivity.

Indeed, in some cultures it is a social advantage, an honor to be sensitive. Peoples living close to the earth esteem their highly sensitive herbalists, trackers, and shamans... Perhaps 'old' cultures with rich artistic, philosophical, and spiritual traditions such as China and Europe can afford to reward sensitivity more than 'new' immigrant cultures... which have rewarded pioneering 'macho' men and 'tough' women who gave little thought to risks in a new land." (Aron, 2002, p. 63)

Owen's sensitivity was apparent early on in his infancy. Owen, a joyful baby, needed additional comforts and highly attuned caregivers who could anticipate and react to his needs before he became overwhelmed.

I noticed when Owen was a toddler he needed a lot of preparatory warning, or time, to ready himself for change. My mom pointed it out to me that his transitions would be smoother if I just gave him more advanced notice. For example, when we played at the park and it was time to leave I could not say, "We are leaving soon," but instead needed to say, "We are leaving in 20 minutes." Followed by, "We are leaving in 10 minutes." "We are leaving in 5 minutes." "Two more minutes..." Until I could say, "It is time to go," by which time he would be prepared and calmly and happily leave with me. If I did not allow this extra time for him to prepare, he would panic, as he was not ready and it would all be happening too fast.

HSC are individuals with a shared trait. It took time for me to learn what Owen's specific characteristics are and I wondered-and worried-as he grew, how he would fare in a school setting. Would the environment be too chaotic and stressful? Would the children be kind to him? I have witnessed a myriad of Owen's experiences and collectively I have learned from these experiences what his needs are, and how I can work to meet them. All of this makes me wonder, "How might his teacher and his classmates learn to understand him and his needs in just a short time?" 


\section{Grade 3}

After three years of Owen crying nearly every day and telling me he hates school, we are standing together in the carpeted hallway of the new school in which I enrolled him.

At Owen's new school his new teacher, Miss Lacey, stands at the doorway to Owen's classroom (as she does at the start and end each day) and greets each student. When the crowd peters out, my son and I step forward together. Owen makes eye contact, showing his significant growth in confidence, but he still stands back a little, out of arms reach. I remember his first week of Kindergarten when his teacher physically held him back, preventing him from coming to me, while he cried and screamed, "Mommy!" in genuine fear of being left without me. In that moment I had stepped around the corner in that cinder-blocked hallway where Owen could not see me, tears pouring down my face, knowing then I was doing the wrong thing for him by ignoring that feeling deep in my belly that screamed, "Don't allow this! It's wrong!" I wondered if Owen was reliving this moment too. We approach the new teacher together-a united front.

Miss Lacey bends at the waist to meet my son eye to eye, smiles warmly at him, and reaches out her hand. She shakes Owen's hand and says the words that convince me this change is exactly the right thing for my sweet boy. "Hi Owen. How are you feeling today?"

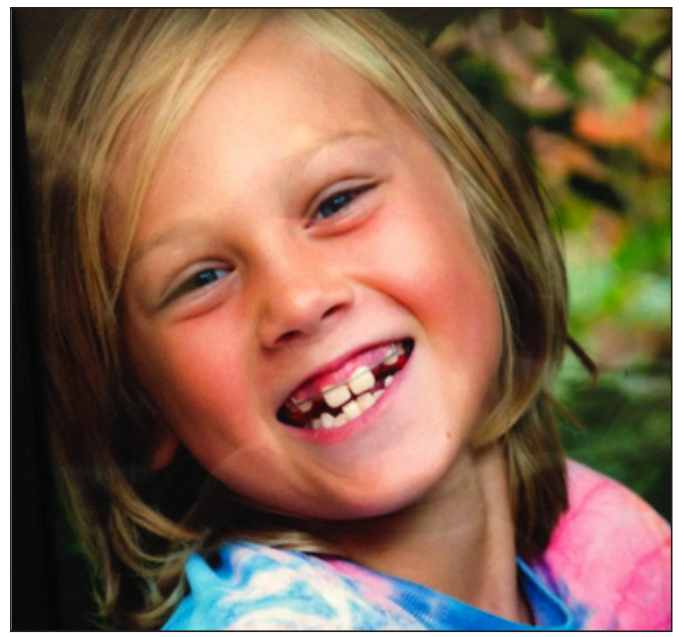

Fig. 2: Owen's Grade 3 school photo, Age 8 
How are you feeling? In the time between his Kindergarten year and Grade 3, that was the first time anyone outside of our family and friends had asked him such a meaningful question. Not, "How are you?" or, "First day, are you excited?" but, "How are you feeling?" In one simple sentence she had conveyed to him that she knew he did indeed have feelings and, in fact, she cared about them. Owen is happy at his new school. When I pick him up he tells me about his day and what he did. I no longer get a list as we travel from the school door to the door of our home of the things he did not like, or thought were unfair or wrong or unkind or inexplicable. He comes home happy. Not sullen and angry. He is my summer child-happy and excited, with twinkling eyes and stories to tell. I have never seen this in him before during the school year. It surprised me to learn he can love school and not just tolerate it. I still find myself basking in the sense of relief that this experience has brought me. "How are you feeling?" This question set the stage for the possibility that my son could, in fact, be himself at school-a feeling human being, and a happy one as well.

This year when I read Owen's neatly typed report card I cried. I cried with the relief in knowing my child is seen. His teacher wrote, "Owen arrives at school each day with a smile and is ready to learn... His attitude toward school is excellent!" Could this be the same child I sent to school in Kindergarten, Grade 1, and Grade 2? Not once this year has Owen complained that he did not want to go to school. Why? What has caused such a dramatic change in his relationship with school? Has it made a difference that his high sensitivity is recognized and attended to each day?

I am reminded of Sandra Finney's (2013) book, Strong Spirits, Kind Hearts: Helping Students Develop Inner Strength, Resilience, and Meaning. She wrote,

Like many teachers, I am convinced that attending to the hearts and spirits of students strengthens their overall abilities to learn and is never time wasted. There is a growing body of evidence suggesting that students who receive support for their personal and spiritual development become better learners. (p. xi)

How does a teacher do this on a level that is more layered and much deeper than may first appear necessary?

\section{Environment}

I am in the crush of milling parents, surrounded by the smiling faces in posters on the walls, on Owen's first day at his new school. There are two doors across the hall from one another, one for each lower elementary classroom. Both are positioned at 45-degree 
angles so I can see into each room as I am standing in the hallway. I notice immediately how different this school looks and feels. Outside of each door is a little table and neatly arranged on it is a communication book. Above that is a white board with welcome messages and notes of information for parents. There is a row of family mailboxes with the children's names labelled neatly beneath each box. Above the mailboxes there is art work. There are potted plants with shiny healthy leaves and benches and chairs along both walls for waiting parents to sit.

I am nervous. My son is anxiously picking his nails and standing protectively close. This school is so different. The carpeted floors dampen the sound and make it feel warmer inside. The walls are papered and decorated with framed photographs of the teachers (and later the students). The classroom Owen will enter is also carpeted. It has big floor-to-ceiling windows in each corner with sheer coloured curtains and plants. Soft couches, chairs, a lamp, and bookshelves fill one corner like a living room. A kitchen area with tables and chairs occupies another corner. There is a pet fish and a homey feel. Most notably it is so much quieter than what we are used to in the chaos of hallway bell times. There is no chaos. There are no bells. I came to discover later that there is often soft classical music playing in the hallways.

Owen entered this new environment with an unpleasant school history, and I learned from Owen's Kindergarten experience, "...with a few bad experiences, HSC are more likely than others to become shy, fearful, or depressed" (Aron, 2002, p. 10). I hoped this change in schools would result in Aron's description that "with a little gentle guidance, they are exceptionally creative, cooperative, and kind - except when overwhelmed..." (p. 10). I knew Owen's best qualities (kindness, compassion, and creativity) related to his sensitivity and, by the time he reached Grade 3, I was feeling desperate for him to experience an environment at school where demonstrating these characteristics felt possible.

\section{Stimulation}

I cannot remember how many times Owen's teachers wrote on his report cards and commented at interview times how they would like to hear him speak more in class. Sometimes he was labelled shy. (He is not shy. He is cautious. They are not the same thing.) He was spoken about as though his quietness needed fixing, and he was openly encouraged to participate more during verbal exchange. Looking back, I wonder why no one asked why he was choosing quiet observation; what he was learning from that vantage point; what reason he had to be silent? Aron (2002) wrote, 
First, most schools are excruciatingly overstimulating..., and the classrooms are usually overcrowded, noisy by design as well as because of the loud voices used, and the days are long. At the same time, they are often boring for HSCs, since they grasp their teachers' messages right away, but these have to be repeated over and over to the other students. Then the HSC's mind wanders, returns, and finds she has missed something, which is also troubling. ... But at school, HSCs are a true minority in the ways they behave. For example, they tend to become quiet and observe the highly stimulating environment. They are left out of the interaction - leave themselves out... Given the above, your HSC is likely to be anxious at school as well as overaroused due to the overstimulation. Overarousal and high anxiety interfere with the expression of social, academic, and athletic skills. As a result, the association of anxiety with school is eventually justified. Your child is trying to be perfect while the body is in a far from perfect state. (pp. 251-252)

In my memory of Owen's early days at school, these points of Aron's certainly feel true. The comments from his teachers were true in that he was not expressing himself freely, he was missing some content during lessons, and he was, in some ways, tuning out. Enabling silence in the classroom can be a hard task. Yet, as Finney (2013) described, comfortable silence is important for children (especially HSC) to thrive. "Show patience and calmness while waiting for students' responses. Allow silence to deepen. Honour the right to pass. An environment where it is all right to be silent is also a place where it is safe to speak" (p. 20). I wonder if Owen's lack of attention at times was his body's way of protecting him from the overstimulation of the environment-an environment with not enough space for silence. Owen's old experiences are in such sharp contrast to the Owen his teacher tells me she sees at his new school. What is different? Why does it seem to work better for him at his new school? In a public school setting where the teacher is assigned a classroom filled with desks, a shortage of budget, and an abundance of children, how can (s)he accommodate high sensitivity too?

\section{Reciprocal Parent/Teacher Learning}

My thoughts of HSC revolve around awareness. Many teachers are interested in "temperament differences and their effects on learning styles" (Aron, 2002, p. 311) and, given the opportunity, may want to learn more about HSC. Aron suggested that teachers work closely with parents of HSC and refer to previous teachers for insights and helpful suggestions. My conversations with Owen's teachers have varied as much as the teachers themselves. I have discovered over time that the more informed I am on high sensitivity, the better I can communicate Owen's needs. It was Owen's preschool teacher, Frances, who introduced me to the concept of high sensitivity. 
I remember Owen's first day of preschool. When the time came to leave Owen, who had been smiling and playing with the other children, little blue fleece sweater zipping around the courtyard, looked up at me, his eyes filled with concern, as if to say, "I was having fun, but you're not leaving me here alone are you?" I smiled at him and walked him to the children at the gate. I was expecting to have to leave and hoped Owen would not cry or make a scene, or insist on leaving with me. When I said goodbye he became anxious. I felt stiff, not wanting to be the parent who had the child with the separation anxiety but knowing I was; he still needed me to feel safe.

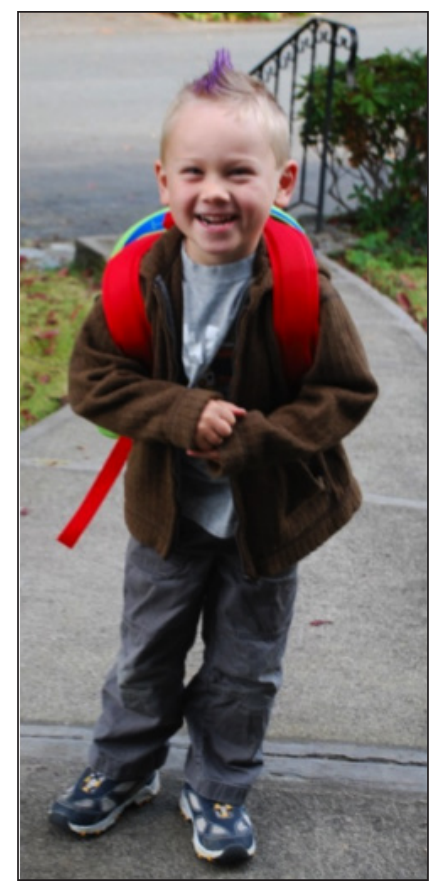

Fig. 3: Owen's first day of preschool

Frances, his teacher, immediately understood what was transpiring between us. I believe she already knew to "[r]emain confident that when [HSC] feel secure, they will have a great deal to share. Indeed they often become the most talkative, creative, and lively students" (Aron, 2002, p. 314). She looked at me and invited me inside. She invited me to stay. I stayed with Owen all that week while he slowly, cautiously entered the preschool world and environment Frances had so carefully and thoughtfully constructed. The next week turned into a month of me staying, followed by two months and then three. When I would feel ashamed that I was still there, she would 
remind me how important this transition period was for him. She reminded me how much it mattered to him, his sense of safety, and his developing self that I was there. She encouraged me to stay for as long as he needed me. Frances also instructed me to very slowly take a little step further away each week: Owen out of my lap and onto the floor in the circle and me into a little chair beside him; me in the chair outside the circle; me away from the carpet and sitting at the little tables; me in the kitchen visible through the pass through, but in the other room; and finally, me leaving the building and going for short walks and increasing the time away each week until I could actually leave and go home and come back at pick-up time. It took a lot of time and attention. It took a lot of patience. That time was what Owen needed, and it was time I could give.

From my relationship with Frances, I later understood that I, too, was shaped in fearful ways by Owen's Kindergarten experience and it took me time to relax and trust that Owen's sensitivity-related needs could be shared. This year, I have experienced Owen's teacher as curious, receptive, and friendly at all times. Maybe it is working well because I, too, feel safe to share my knowledge about high sensitivity with her. I have discovered that learning and teaching about HSC is a process of reciprocity.

\section{Discipline}

In my earlier story of Owen in Kindergarten and his intense worries about breaking rules, it became apparent to me that school, with rules and group lectures, would be difficult for him. I struggle now to recall a time, in his earliest formative years, when I needed to reprimand Owen. He simply did not do things he ought not to be doing. If I explained the reasoning of things to him, pre-emptively, I do not remember ever having to follow up with another conversation repeating the same information. Nor did I say to Owen the common "do nots" of average parenthood. However, we struggled with other things - acknowledging, with a wave or smile, someone when they say hello to you (a major feat!), the frustration of following rules when those around you are not (e.g., cheating and cutting in line), watching others being rewarded/noticed for their speed (e.g., hand raising, first in line), and kids being unkind, usually to others. It was, and continues to be, a painful and challenging experience for Owen. As I write, Owen is neatly printing a wish list of gifts for all of his classmates, just in case he wins an online contest for which the prize is 107 Lego characters.

I remember in the early weeks of Owen's preschool how much he loved to dress up in a purple wizard's robe covered in big yellow stars with a matching pointy hat. He would put it on first during playtime and wear it while he built his block creations. Some of the other little boys began to tease him. Frances noticed this and after a couple 
of days she collected all of the children on the carpet for circle time. She talked with the children. I noticed how she asked the children a lot of questions and left many parts of the conversation open ended. It was not what I had expected. I remember speaking with her after, inquiring about her technique (perhaps an indirect way of asking, "Is that enough?" "Where was the lecture, the reprimand?"). Frances replied that I should not worry, that the children understood what she was saying. I waited and I watched. After a day or two the children did, indeed, stop teasing Owen. In Frances' approach to the situation no one child, or group, had been singled out as having misbehaved. She chatted with them and asked them questions centred on kindness and freedoms of expression. I wonder if Owen was even aware the conversation had been sparked by his love of the purple wizard's suit?

In contrast, the rules and strict one-size-fits-all approach to discipline I observed in Owen's earliest experiences at school was very difficult for him. Could it be true that, because he did not need rules the way some other children might, he felt the consequences unfitting and harsh? Aron (2002) described it this way:

...There are more demands and punishments at school, none of them adjusted for the sensitivity of your child. HSCs are usually very conscientious about meeting every demand of school authorities. When an entire class, or your HSC personally, receives a rebuke or punishment, your child is probably crushed by the intensity of message.... (p. 250)

For Owen, watching other children breaking rules and experiencing consequences as a result was a harsh reality. "Never use harsh discipline on HSCs... For some, just knowing they made a mistake will reduce them to tears" (p. 315). I watched Owen not breaking rules but being included in the class scolding. The unfairness of this was something he began to talk about by Grade 2. Prior to that, I wonder, was he trying to be so good-so that he could help the other children avoid getting into trouble-because it pained him so much to observe how the action/consequence sequence unfolded?

At his new school, he says his teacher is always nice and does not ever shout at any of them. I have observed a few quiet conversations, seated at a table and at child's level, in private areas in the school. Sometimes the children, it appears, are sorting out their own concerns with each other and other times it is teacher and student(s). Owen no longer brings home stories of injustice and I see this as a very good sign that Owen is experiencing rules and consequences at his new school in a different way than previously. 


\section{Friendship}

Early on in Kindergarten, Owen established a friendship with a boy named Kieran. Owen had many friends and made friends easily at school, but we knew from preschool that he needed one person, his person, to feel really secure. At public school this person was Kieran. Aron (2002) wrote, "HSCs thrive in one-on-one relationships and usually need only one good friend for their social and emotional well-being, but that one is essential" (p. 316). I do not know that either boy was ever aware of the role Kieran played. When the boys were split in Grade 3, Owen was devastated. His teacher said she did not see them playing together and did not see the relationship, I suppose, as being anything special or out of the ordinary. But it was. When Owen was fearful at school he knew Kieran was a safe person to be with because Kieran was not afraid. Owen also recognized Kieran to be safe because he, too, was a rule follower and Owen knew he would not get into trouble for misdeeds by spending his time with him. I also knew Kieran to be kind, consistently, to Owen. This friendship was something Owen and I talked about during times of social difficulty with other children in our neighbourhood. Kieran was his person.

Dissimilarly, in Owen's new school, the environment is more conducive to meeting his needs as an HSC, and as a result his need for one-on-one friendship has diminished. I have come to understand that as one need is accommodated other needs may be back-grounded in response. As the needs of HSC are interdependent, or interrelated, it makes sense to find as much of a balance as possible in meeting all of HSC needs simultaneously.

Owen is deeply impacted by the emotional interactions and stresses of others. "HSC is going to feel stronger emotions. Sometimes it's intense love, awe, or joy. But because all children are dealing with new, stressful situations every day, HSCs will also have to feel fear, anger, and sadness, and feel these more intensely than other children" (Aron, 2020, p. 9). It is a struggle for me to help him differentiate his emotions from the emotions of others. Aron explained why this is so hard, "Because of these strong feelings and deep thought, most HSCs are usually empathic. So they suffer more when others suffer and become interested early in social justice. They are also brilliant interpreters of what is happening..." (Aron, 2002, pp. 9-10). This has proven to be one of the most difficult aspects of school for Owen and emphasizes why a single trusted friendship, like that which he has with Kieran, is so valuable. 


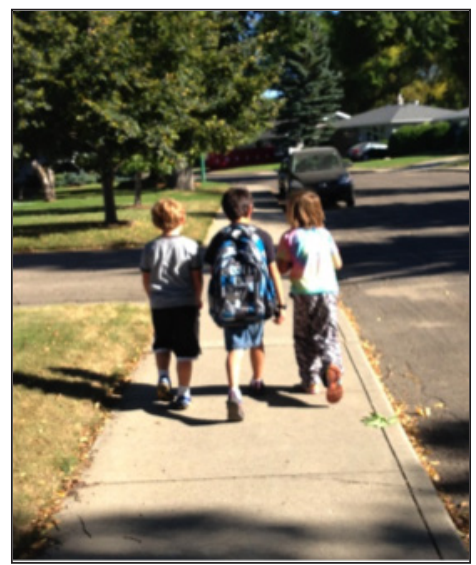

Fig. 4: Owen, his brother Lucas, and Kieran

\section{Conclusion}

Owen, as I shared in my stories, held in his feelings at school and expressed them at home with crying and sadness, anxiety and stress. Another HSC may react with angry outbursts, for example, when stressed or overstimulated-it depends on the child. But, what all HSC share within their trait of high sensitivity are: emotions experienced more intensely, sharp observation skills and perception abilities (Owen knows what is happening in every corner in a shared space), gifts related to creativity, and deeply refined and genuine empathy. All HSC, like Owen,

....are those born with a tendency to notice more in their environments and deeply reflect on everything before acting...As a result, [they] tend to be empathic, smart, intuitive, creative, careful, and conscientious... They are also more easily overwhelmed by 'high volume' or large quantities of input arriving at once. They try to avoid this, and thus are seen to be shy or timid... When they cannot avoid overstimulation, they seem easily 'upset' and 'too sensitive.' (Aron, 2002, p. 7)

How each HSC demonstrates these characteristics is individualistic. Quiet or social, HSC are noticed for their acute sense of justice and their concern and compassion for others. It is the intensity with which they feel and demonstrate these things that makes HSC uniquely different.

Realizing that HSC needs are not independent of one another, it is easier to understand how relationships with teachers are dependent on changes in environment, 
stimulation, parent/teacher learning, discipline, and friendship. There are so many small and simple pieces of understanding that teachers can incorporate into their methods of practice that will allow the HSC of the world to shine as bright and vibrantly as Owen does now. In a larger context, teachers are in a position to include attending to HSC as a part of their daily classroom practice and, in doing so, they will raise the bar for which all students' needs for wellness at school may be met.

My experiences of Owen's primary years in school have taught me more about his needs as a HSC. I have also learned about the richness his presence in the classroom creates. He is well loved by his classmates and thriving at his new school. In return for the compassionate attention he receives, he has come into full bloom and now is able, and feeling safe enough, to offer the wholeness of himself and the gifts of his sensitivity.

I offer my stories of experience as an invitation for deeper attention to how highly sensitive children present in a classroom, what their needs are, and how HSC can be included in the school landscape. It is my belief that such careful attending will have a profound impact on their lives in and out of the classroom.

\section{Notes}

1. The results of an assessment using a Sensory Processing Measure form showed Owen is functioning in a normal range.

2. Rae is a pseudonym used to protect the identity of the child. All other names in this article are real names.

\section{References}

Aron, E. (2002). The highly sensitive child: Helping our children thrive when the world overwhelms them. New York: Broadway Books.

Finney, S. (2013). Strong spirits, kind hearts: Helping students develop inner strength, resilience, and meaning. New York: Rowman \& Littlefield.
Silverstein, S. (1974). Where the sidewalk ends. New York: Harper \& Row. 


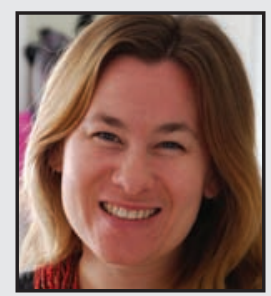

Mandy Hollands is a teacher and a graduate student in the Department of Curriculum Studies at the University of Saskatchewan. She is specializing in Highly Sensitive Children with the intention of creating teacher, parent, and community understanding of high sensitivity. Mandy is also interested in raising the standard of kindness, compassion, and love in classrooms, thus meeting the emotional needs of all children. Creating opportunities for fine arts, creativity, and nature in classrooms remains a passion. Mandy plans to work as an expressive arts therapist and education consultant following the completion of her studies. 